\title{
Diversity and Distribution of Liverworts in Gujarat - Current Status
}

\author{
Dharmendra Govindlal Shah" and Rakesh V. Gujar \\ Ecotoxicology \& Lower Plants Lab., Dept of Botany, The Maharaja Sayajirao University of Baroda, Vadodara 390 002, Gujarat, India
}

Article history

Received: 9 March 2016

Accepted: 27 March 2016

Published: 11 April 2016

(C) Shah and Gujar (2016)

Special Section: New Frontiers in Cryptogamic Botany

Section Editor

Afroz Alam

Publisher

Horizon e-Publishing Group

Corresponding Author

D. G. Shah

凶shahdhamu@gmail.com

\begin{abstract}
The liverwort diversity in Gujarat has been mostly neglected by biodiversity researchers across the state and more than $75 \%$ of the districts have never been investigated for their bryo-diversity. A detailed study was conducted during 2013-2015 covering 75 locations spread over 31 of the 33 district of the state to understand the diversity and distribution of liverworts in the state. The liverwort diversity in the state now stands at 22 species of which 16 species were located in the current study. Genus Riccia has the maximum diversity in the state. Cyathodium cavernarum Kunze. was the most widely distributed species being located in 17 out of the 31 districts studied. Taxilejeunea ghatensis, Riccia crystallina and R. cavernosa are new records to the state. Genus Marchantia is also being reported for the first time. Dangs and Panchmahal districts have the highest liverwort diversity with 10 species each.
\end{abstract}

Keywords

Liverwort; Gujarat; Diversity; Riccia

Shah, D. G. and R. V. Gujar. 2016. Diversity and Distribution of Liverworts in Gujarat - Current Status. Plant Science Today 3(2): 124-128. http://dx.doi.org/10.14719/pst.2016.3.2.208

\section{Introduction}

Liverworts constitute one of the three major groups of bryophytes. They are estimated to be around 391 genera and 5000 species (Stotler et al., 2009). They are found in a large variety of habitats ranging from rock crevices, old walls, bark of trees to road cuts. Like other group of bryophytes the gametophyte is the independent and dominant phase of the life cycle while the sporophyte is subsidiary and dependent on the gametophyte for its nutritional needs. 675 species in 121 genera of liverworts have been described from different parts of India (Dandotiya et al., 2011). According to Singh (2001) the eastern Himalayas harbor about 64 percent of the liverworts while the Western Ghats and the Western Himalayas have about 33 and 28 percent of reported liverwort taxa of the country. The western part of the country which includes Gujarat, Maharashtra and Rajasthan has received little attention from bryologists partially due its arid climate (Afroz et. al., 2011, Lavate et al., 2015).

In Gujarat till 2000, only 22 species of bryophytes which included 11 species of liverworts had been reported from different parts of the state (Anon. 1996). Chavan (1937a, 1937b) pioneered bryophyte research in the state. He along with his co-workers (Chavan and Mahabale, 1945) reported 19 species of bryophytes from different locations of Gujarat including Abu and Mahabaleshwar which were earlier part of the presidency of Bombay. Out of the 19 species reported by them 9 were liverworts including Plagiochasma appendiculatum, Asterella angusta, Riccia discolor, $R$. cruciata, $R$. gangetica, $R$. melanospora, Cyathodium barodae, $C$. tuberosum and Fossombronia himalayensis. Another contribution to the bryophyte flora of the state was made by Patel in 1977. While working on the algal diversity of different parts of Gujarat, he 


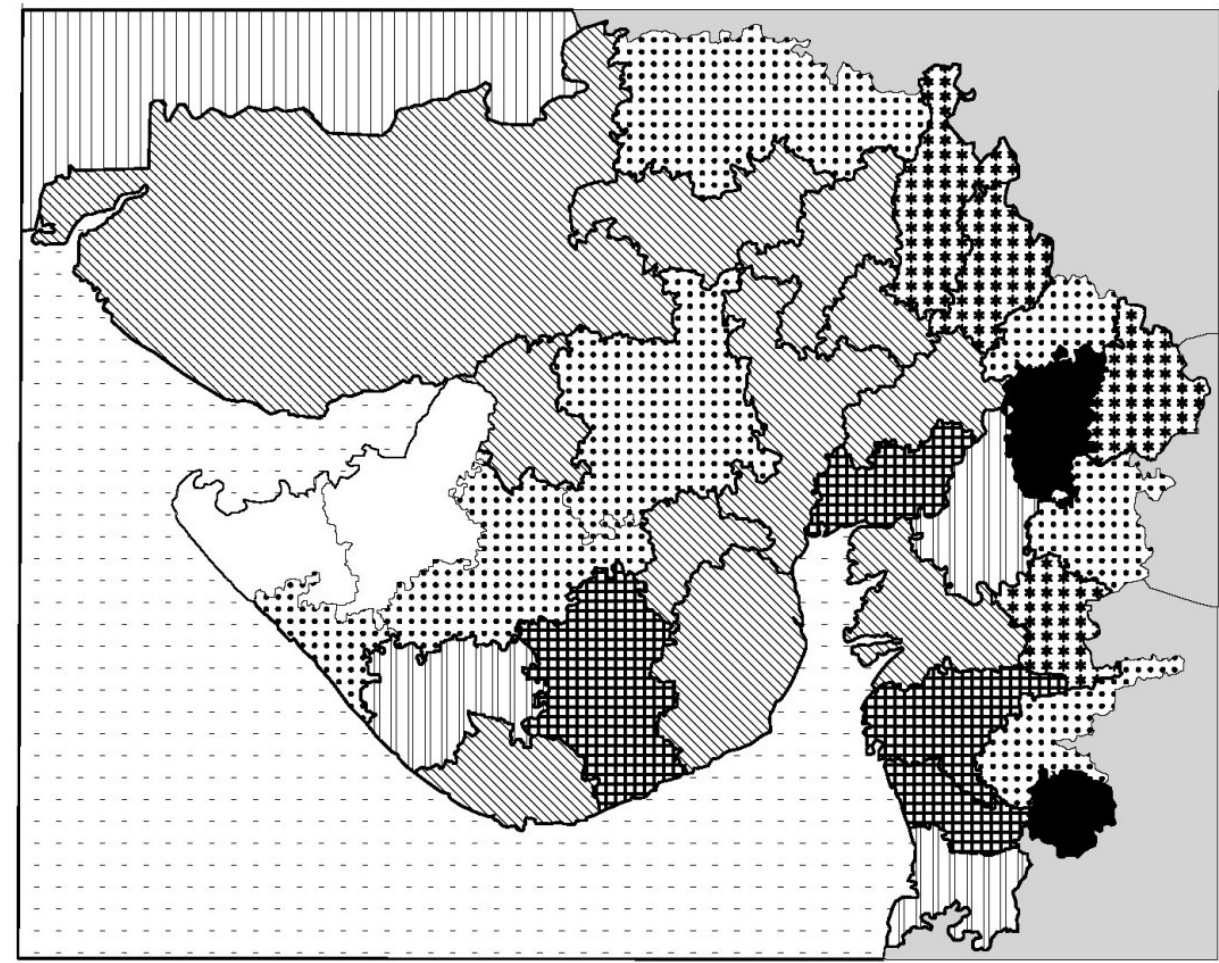

No. of liverwort species

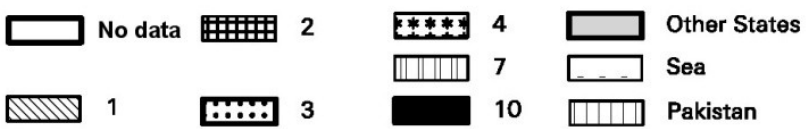

Fig. 1 Distribution of liverworts in different districts of Gujarat

made a discovery of the genus Riella in the state and reported the presence of Riella affinis and $R$. cossoniana (Patel 1977a; Patel, 1977b). The major contribution to the liverwort flora of the state was made by Chaudhary et al. (2006). Their work, published in the form of a book 'Bryophyte flora of Gujarat - (India)' was the culmination of a survey undertaken from 1999 to 2004. They reported 13 species of liverworts including Lejeunea aloba, Targionia hypophylla, Plagiochasma rupestre, $P$. microcephalum, $P$. intermedium, Riccia grollei, $R$. billardieri and $R$. gangetica for the first time from Gujarat. Their work had however, covered only 10 districts of the state and several districts like Surat, Narmada, Aravalli and Vadodara which had a good forest cover were not investigated. Chauhan (2009) indicated that there was a huge gap in information on the diversity and distribution of bryophytes in the state. To fill the gap, present study was conducted between 2013 and 2015.

\section{Materials \& Methods}

The study incorporated detailed field studies as well as lab analysis. A total of 75 localities spread over 31 out of the 33 districts of the state were visited. A total of 90 days of field work was conducted during the two year study. They were visited during monsoon (July-Sept) and post monsoon (Oct-Jan).

\section{The Study area}

The state of Gujarat is situated on the western coast of India between $22^{\circ} 07^{\prime} \mathrm{N}$ and $24^{\circ} 43^{\prime} \mathrm{N}$ latitude and $68^{\circ} 10^{\prime} \mathrm{E}$ and $74^{\circ} 29^{\prime} \mathrm{E}$ longitude (Anon, 2011a). It is bounded by the Arabian Sea on the west, Pakistan on the Northwest, Rajasthan on the North and Northeast, Madhya Pradesh to the East and Maharashtra to the South. It has a coastline of about $1650 \mathrm{~km}$, land area of 196,024 sq. km. and population of 60,383,628 which accounts for approximately 5 percent of total population of India (Anon, 2011b). The state is located on the tropic of cancer and shows sub-tropical type of climate. Ecologically, Gujarat is gifted with a diversity of natural ecosystems ranging from desert, semi-arid, mangroves, coral-reefs and forests with dry deciduous, moist deciduous and evergreen trees. The major forests in Gujarat are concentrated along the eastern tribal belt of the state.

\section{Collection strategy and sample collection}

Random sampling strategy was employed for the collection of the samples from the different sites. All the liverworts encountered during the field visit were sampled. Wherever possible the samples with the sporophyte were collected. The geographic coordinates of the site were collected using a Garmin E-trex10 GPS receiver. 
Table 1. Distribution of liverworts in Gujarat according to the past and present studies

\begin{tabular}{|c|c|c|c|c|c|}
\hline \multirow[b]{2}{*}{ Sr. No. } & \multirow[b]{2}{*}{ Species } & \multirow[b]{2}{*}{ Family } & \multicolumn{3}{|c|}{$\begin{array}{l}\text { Number of Districts showing distribution } \\
\text { of the species. }\end{array}$} \\
\hline & & & $\begin{array}{c}\text { Only from } \\
\text { past } \\
\text { studies }\end{array}$ & $\begin{array}{l}\text { Past distribution } \\
\text { confirmed in } \\
\text { current } \\
\text { study }\end{array}$ & $\begin{array}{c}\text { Only from } \\
\text { current } \\
\text { study }\end{array}$ \\
\hline 1. & Rectolejeunea aloba (Sande Lac.) Stephani. & Lejeuneaceae & - & 3 & 1 \\
\hline 2. & *Taxilejeunea ghatensis Verma \& S.C. Srivast. & Lejeuneaceae & - & - & 1 \\
\hline 3. & Fossombronia himalayensis Kash. & Fossombroniaceae & - & 1 & 1 \\
\hline 4. & *Marchantia sp. & Marchantiaceae & - & - & 1 \\
\hline 5. & Targionia hypophylla L. & Targioniaceae & 2 & 1 & - \\
\hline 6. & Cyathodium cavernarum Kunze. & Cyathodiaceae & 1 & 3 & 14 \\
\hline 7. & Cyathodium tuberosum Kash. & Cyathodiaceae & 1 & - & 2 \\
\hline 8. & Asterella angusta (Steph.) Kachroo & Aytoniaceae & - & 2 & 1 \\
\hline 9. & Plagiochasma rupestre (Forst.) Steph. & Aytoniaceae & 1 & - & 1 \\
\hline 10. & $\begin{array}{l}\text { Plagiochasma appendiculatum Lehm. et. } \\
\text { Lindenb. }\end{array}$ & Aytoniaceae & 3 & - & - \\
\hline 11. & Plagiochasma microcephalum (Steph.) Steph. & Aytoniaceae & 1 & - & 2 \\
\hline 12. & Plagiochasma intermedium Lindenb. \& Gott. & Aytoniaceae & - & 1 & - \\
\hline 13. & Riccia discolor Lehm. \& Lindenb. & Ricciaceae & 1 & 1 & 1 \\
\hline 14. & Riccia grollei Udar & Ricciaceae & 1 & - & - \\
\hline 15. & Riccia billardieri Mont. et Nees. & Ricciaceae & 3 & 5 & 6 \\
\hline 16. & Riccia gangetica Ahmad. & Ricciaceae & 1 & 1 & 2 \\
\hline 17. & *Riccia cavernosa Hoffm. & Ricciaceae & - & - & 4 \\
\hline 18. & *Riccia crystallina $\mathrm{L}$. & Ricciaceae & - & - & 1 \\
\hline 19. & Riccia cruciata Kash. & Ricciaceae & 1 & - & - \\
\hline 20. & Riccia melanospora Kash. & Ricciaceae & 1 & - & - \\
\hline 21. & Riella cossoniana Trab. & Riellaceae & 1 & - & - \\
\hline 22. & Riella affinis Howe and Underw. & Riellaceae & 1 & - & - \\
\hline
\end{tabular}

Note: Family names are according to Stotler et. al. (2009)

* New records for the state.

Photographs of the samples in their natural habitat were taken. The samples were collected in brown paper bags, labeled and air dried for further analysis and voucher preparation. The collection method given by Glime (2013) was followed with minor modifications. More than 145 samples were collected during the study.

\section{Laboratory analysis and identification}

The micro-morphological and anatomical features of the plants were observed under Leica SD6 stereo binocular microscope and the photographs of the relevant parts were taken with the help of a 3.2 MP Tucsen camera. Preliminary identification of the plants was carried out using available standard literature (Bapna and Kachroo, 2000a; 2000b; Kashyap, 1929; 1932; Singh, 2014). The samples were then taken to the National Botanical Research Institute (N.B.R.I), Lucknow where the identity was confirmed after consultation with experts. The Vouchers were deposited in the herbarium of Maharaja Sayajirao University of Baroda (BARO).

\section{Results and Discussion}

A total of 18 species of liverworts were collected out of which 15 were identified till the species level while one was identified till the genus level only, thus a sum of 16 taxa were identified. Two specimens could not be identified due to the lack of sexual as well as asexual reproductive structures. Table 1 lists all the 22 species that have been reported in the past as well as in the present study. The table provides information on the number of districts from which the species are known only from the past study, only from the current study and the number districts where past distribution has been confirmed in the current study. Taxilejeunea ghatensis, Riccia crystallina and $R$. cavernosa are new records for the state. 

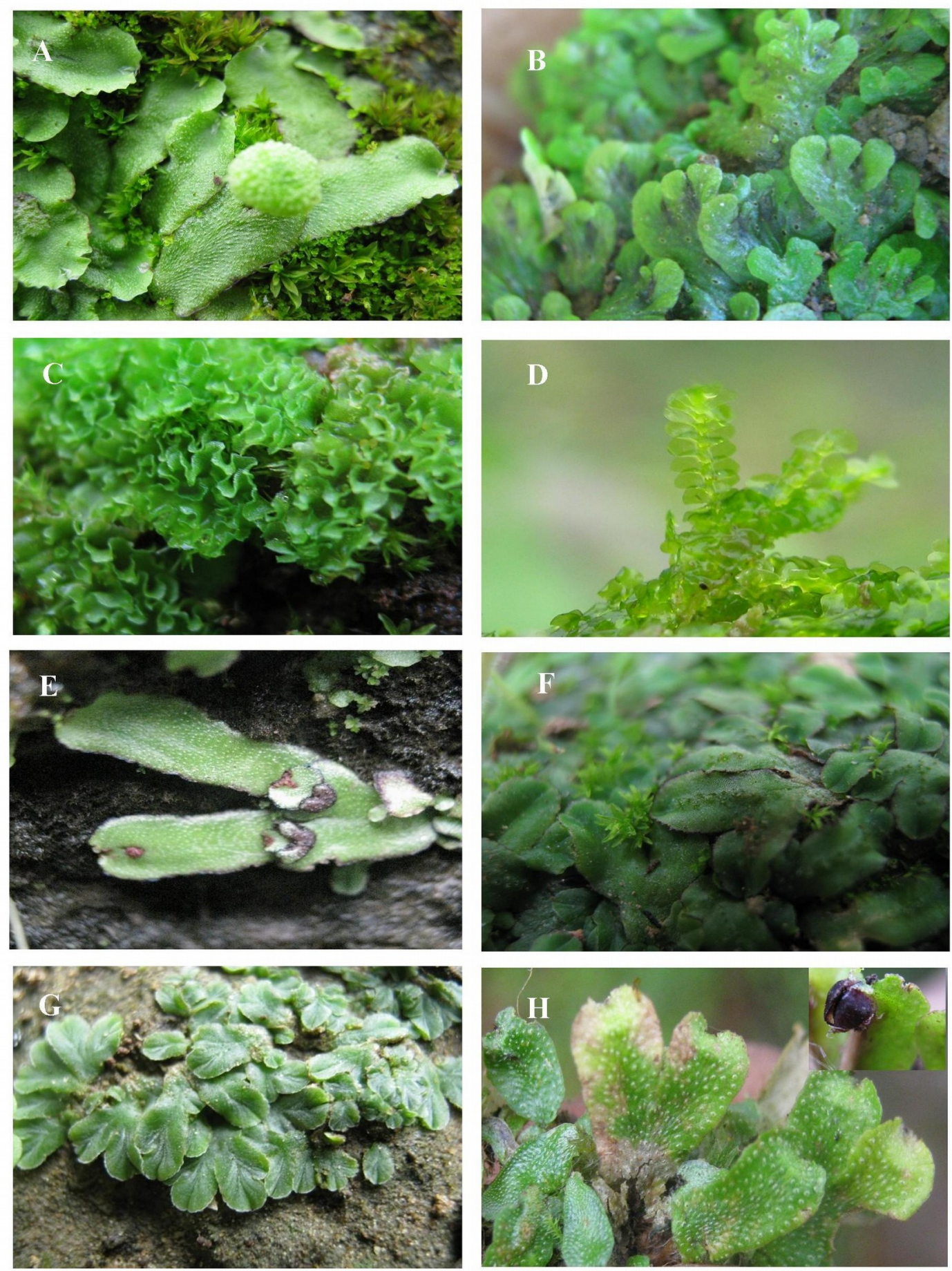

Fig. 2:- Liverwort species found in Gujarat A. Asterella angusta (Steph.) Kachroo.; B. Cyathodium cavernarum Kunze.; C. Fossombronia himalayensis Kash.; D. Rectolejeunea aloba (Sanda Lac.) Stephani.; E. Plagiochasma appendiculatum Lehm. et Lindenb.; F. Riccia billardieri Mont. et Nees.; G. Riccia gangetica Ahmad.; H. Targionia hypophylla L .

Marchantia with gemma cup was also collected during the study but due to absence of sexual reproductive features the exact species could not be identified. Riccia was the most abundant genus with 5 species; however, three earlier reported species of Riccia could not be collected during the current study. The most commonly found liverwort was Cyathodium cavernarum which was observed in 17 of the 33 districts that were surveyed. On the other hand Taxilejeunea ghatensis, Targionia hypophylla, Plagiochasma rupestre, $P$. intermedium and Riccia crystallina were found in one district only. Fig. 1 depicts a few of the liverworts that were found during the study.

The distribution of liverworts across the state has been depicted in fig. 2 . The paper reports the distribution of liverworts in 20 districts for the first time. Eleven districts show the presence of 
only single species of liverwort while 4 districts show the presence of two species of liverworts. Most parts of Saurashtra and Kachchh show low liverwort diversity. These areas are characterized by low rainfall. Girnar Hills in Junagadh district is however the highest point in Gujarat characterized by high liverwort diversity due to high moisture during the rainy season. Dangs and Panchmahal district with 10 species of liverworts has the highest diversity in the state. In addition to Junagadh, Valsad and Vadodara districts also report the presence of seven species of liverworts. The eastern tribal belt of Gujarat shows moderate to high diversity of liverworts.

Six earlier reported species could not be located in the current study. Two species of Riella have been reported from Nal Sarovar and Lake Kanewal. However, both these locations could not be investigated in detail due to high level of water. Further significant changes have occurred in both the localities, and as a result the localities are facing severe anthropogenic influence. Similarly, few other species, earlier reported from Pavagadh in Panchmahal district and Saputara district, could not be collected. Both of these locations have seen huge development in the past several years and are important sites for religious pilgrimage and tourists respectively. More than 3 lakh visitors visit each of these locations every year and though these sites were surveyed several times all the species could not be found. In several of the districts only a few sites have been visited during the study and hence, there are possibilities that some bryophytes may have been overlooked during the study. This highlights the need for sustained bryophyte studies in the state.

\section{Acknowledgments}

The authors are thankful to Gujarat Biodiversity Board (GBB) for financial support in the form of a one-year project (GBB/ResearchStudies/73940/2013-14) and to the departmental UGC-DRS scheme for support of additional field work. The authors acknowledge the immense contribution of Dr. A. K. Asthana and Dr. Vinay Sahu, Bryology Lab, National Botanical Research Institute, Lucknow, for helping in identification of the specimens. The authors also acknowledge the efforts of the two anonymous reviewers who have immensely improved the manuscript.

\section{References}

Afroz, A., V. Sharma, and S.C. Sharma 2011. Bryoflora of Ranthambhore Tiger Reserve, Rajasthan (India). Archr Bryol 106: 8

Anon. 1996. The Biological Diversity of Gujarat: Current knowledge. Gujarat Ecology Commission, Vadodara, Gujarat.

Anon. 2011a. State of Forest Report, 2011. Forest Survey of India. Ministry of Environment and Forests, Dehradun, 35-40 pp.
Anon. 2011b. Census of India, Village and town Directory, Village and town wise primary census abstract Govt. of India. (CD)

Bapna, K. R. and P. Kachroo. 2000a. Hepaticology in India Vol-1, Himanshu Publications, Udaipur and New Delhi, $439 \mathrm{pp}$

Bapna, K. R. and P. Kachroo. 2000b. Hepaticology in India Vol-2, Himanshu Publications, Udaipur and New Delhi, $491 \mathrm{pp}$

Chaudhary B. L., T. P. Sharma and S. Charu. 2006. Bryophyte Flora of Gujarat (INDIA), Himanshu Publicatons, Udaipur, $197 \mathrm{pp}$.

Chauhan, S. 2009. Liverwort diversity of the $M . S$. University Campus, M.Sc. Dissertation, Department of Botany, The M. S. Univ., Vadodara, 33 pp

Chavan, A. R. 1937a. A Morphological study of Cythodium barodae. Am J Bot 24(8): 484 - 492. doi: $10.2307 / 2437067$

Chavan, A. R. 1937b. A new species of Cythodium from India. The Bryologist 15(3): 57-60. doi: 10.1639/00072745(1937)40[57:ANSOCF]2.0.CO;2

Chavan, A. R. and T. S. Mahabale. 1945. Distribution of Liverworts in Gujarat. Proc. 32nd Indian Science Congress, Nagpur. 70

Dandotiya D., H. Govindapyari, S. Suman and P. L. Uniyal. 2011. Checklist of the bryophytes of India. Arch Bryol 88:.1-126.

Glime, J. M. (2013) Field Taxonomy and Collection Methods. Chapt. 1-1. In: Glime, J. M. Bryophyte Ecology. Volume 3.- Methods. Ebook sponsored by Michigan Technological University and the International Association of Bryologists. Ebook last updated 16 August 2013 and available at <www.bryoecol.mtu.edu>.

Kashyap S.R. 1929. Liverworts of the Western Himalaya and Panjab Plain Part 1. The University of Panjab, Lahore.

Kashyap S.R. 1932. Liverworts of the Western Himalaya and Panjab Plain Part I1. The University of Panjab, Lahore.

Lavate, R., S. Patil, , M. Dongare, , S. Sathe, and S. Magdum, 2015. Pallavicinia lyellii (Hook.) Gray, (Pallaviciniaceae): an addition to the hepatic flora of Maharashtra, India. Plant Science Today 2(4): 192196. doi: 10.14719/pst.2015.2.4.167

Patel, R. J. 1977a. On Riella affinis (Hepaticae) from India. Aquatic Botany. 3(3): 287-290. doi: 10.1016/03043770(77)90031-6

Patel, R. J. 1977b. On Riella cossoniana Trab. New record from Gujarat state. Journal of Indian Botanical Society 56(3): 237-239.

Singh, D.K. 2001. Diversity in Indian Liverworts: their status, vulnerability and conservation. In: Perspectives in Indian Bryology. V. Nath and A.K. Asthana (Eds). Bishen Singh Mahendra Pal Singh, Dehradun. P. 325 - 354

Singh, S. K. 2014. An appraisal of genus Riccia in India with a note on diversity and distribution of species, Int. J. Sustainable Water and Environmental Systems 6(1):35-43

Stotler, B. C., R. E. Stotler, and D. G. Long. 2009. Morphology and classification of Marchantiophyta. In: Bryophyte biology. B. Goffinet and Shaw Eds. Cambridge University Press, New York. p 1-53. 